\title{
A Self-Compassion Intervention Program for Children in Greece
}

\author{
Eirini Karakasidou*, Georgia Raftopoulou, Anastassios Stalikas \\ Department of Psychology, Panteion University of Social and Political Sciences, Athens, Greece \\ Email: *irenekarakasidou@yahoo.com
}

How to cite this paper: Karakasidou, E. Raftopoulou, G., \& Stalikas, A. (2021). A Self-Compassion Intervention Program for Children in Greece. Psychology, 12, 1990-2008.

https://doi.org/10.4236/psych.2021.1212121

Received: November 5, 2021

Accepted: December 13, 2021

Published: December 16, 2021

Copyright $\odot 2021$ by author(s) and Scientific Research Publishing Inc. This work is licensed under the Creative Commons Attribution International License (CC BY 4.0).

http://creativecommons.org/licenses/by/4.0/ (c) (i) Open Access

\begin{abstract}
The current study investigates the effectiveness of an online four-week Self-Compassion Program designed for enhancing self-compassion, positive emotion and mental resilience while reducing isolation, over-identification, self-judgment, trait anxiety, and state anxiety. Sixteen Greek children, aged 8 - 11 years old, were recruited and randomly assigned to a control and an intervention group $\left(N=16, M_{a g e}=9.63\right)$. The participants completed online batteries one week before and one after the intervention to measure the desired variables. The results showed that the program strengthened self-compassion levels, increased positive emotions and mental resilience rates, and reduced isolation, over-identification, self-judgment, trait anxiety, and state anxiety levels. Overall, the results provided clear evidence of the benefits of self-compassion and proved that self-compassion can be taught and used as a tool for promoting and enhancing children's mental health.
\end{abstract}

\section{Keywords}

Self-Compassion, Intervention Program, Positive Psychology, Children, Adolescents

\section{Introduction}

\section{Self-compassion}

Research has shown that high levels of self-compassion are associated with high levels of well-being (Neff, 2011; Zessin et al., 2015). People with higher levels of self-compassion report lower levels of depression, anxiety, perfectionism, suspicion, and thought suppression than those without the characteristic (Neff, 2003a; Neff \& Kirkpatrick, 2007, 2008; Van Dam et al., 2011).

In one of the first empirical studies conducted on self-compassion, Neff (2003a) found that higher levels of self-compassion were associated with higher 
levels of emotional, social connection and life satisfaction. Also, high levels of self-compassion seem to be associated with high levels of happiness (Campos et al., 2015), curiosity and originality (Yang et al., 2016), creativity (Zabelina \& Robinson, 2010), hope (Umphrey \& Sherblom, 2014) and resilience (Neff \& McGee, 2010).

In addition, self-compassion seems to have many psychological benefits associated with positive psychology (Seligman \& Csikzentmihalyi, 2000), such as optimism, wisdom, curiosity and exploration, personal initiative and positive influence (Neff, Rude, \& Kirkpatrick, 2007). Moreover, self-compassion is associated with various aspects of emotional intelligence-better emotional coping skills, emotional clarity, and the ability to recover from negative emotional states (Neff, 2003a). It is also an essential factor in understanding mental health, as it seems to play a crucial role in the way people manage unpleasant and adverse events (MacBeth \& Gumley, 2012; Neff, 2003a).

\section{The value of self-compassion for the younger population}

Research in adults and adolescents has shown that self-compassion is associated with many dimensions of psychological well-being, such as higher optimism and happiness and lower stress and depression (Barnard \& Curry, 2011; MacBeth \& Gumley, 2012; Neff, 2011; Zessin et al., 2015). Neff (2003a) believed that self-compassion exists throughout development and stems from the individual's interaction with their caregiver and attachment style in infancy. However, little is known about childhood self-compassion and how it develops concerning other aspects of social and emotional well-being.

According to Neff \& McGee (2010), self-compassion is an essential predictor of adolescents' mental health. Adolescents with higher self-compassion reported lower levels of depression and anxiety and greater feelings of social connection (Neff \& McGee, 2010). Self-compassion can provide a way for teens to experience positive feelings about themselves without getting involved in the complex process of self-assessment and evaluation. Bluth and Blanton (2015) highlighted the protective role of self-compassion in adolescent anxiety and depressive symptoms, as higher levels of self-compassion were found to be associated with lower levels of perceived stress and higher levels of life satisfaction in adolescents aged 14 and 18 years.

Zeller and his colleagues (2015) found that higher levels of self-compassion were a predictor of lower levels of psychopathology (depression, post-traumatic stress, panic and suicide) following a traumatic event in a sample of adolescents aged 15 - 19 in Israel. In this study, the protective role of self-compassion against the potentially adverse effects of the traumatic event was reported. Higher levels of self-compassion at two points in time predicted lower levels or less increase in post-traumatic stress and panic symptoms in the future. In addition, self-compassion was negatively associated with depression and suicidal ideation (Zeller et al., 2015).

The findings are similar for adolescents, with those with high self-esteem re- 
porting less depression, stress and anxiety (Bluth \& Blanton, 2015), less substance use problems (Tanaka et al., 2011) and less likely to experience shame or fear failure (Mosewich et al., 2011). These findings suggest that self-compassion during adolescence is an endearing trait, as it appears to be a protective factor in specific developmental disorders (Bluth et al., 2018). The only up-to-date study on stress-related biomarkers in adolescent self-compassion showed a trend toward overall lower normal stress responses (i.e., lower systolic blood pressure, increased heart rate, and cortisol output) in the group with higher self-compassion (Bluth et al., 2017).

Adolescence is a critical period characterized by vulnerability to psychological stress. It, therefore, is an essential stage in promoting mental well-being and early psychological intervention to prevent the person from developing psychological problems (Xavier et al., 2015). Additionally, several surveys demonstrated a strong correlation between self-compassion and well-being in younger populations. It appears that self-compassion may be a protective factor against depression for children and adolescents. Stolow and his colleagues (2016) examined self-compassion as a predictor of depressive symptoms in children and adolescents. The findings showed that children and adolescents have higher levels of a combination of kindness, common humanity and mindfulness (SCS-POS). The results also showed a more significant reduction in depressive symptoms over time than those with lower levels of these positive aspects of self-compassion. At the same time, SCS-POS and self-esteem showed a protective function for depressive symptoms in children and adolescents. The results were consistent at all ages and genders, suggesting that it may be widely applicable to boys and girls aged 9 to 16 years (Stolow et al., 2016).

Bluth and Blanton (2015) studied 90 adolescents from a private high school and a public high school in the southern US. They explored the differences in gender self-compassion and adolescence and their relationship to emotional well-being. Their findings showed differences between gender and age in self-compassion and emotional well-being between high school and high school. Specifically, high school girls reported significantly lower self-compassion and worse emotional well-being than high school girls and boys from both schools (Bluth \& Blanton, 2015). It appears that self-compassion has the potential to protect older adolescents when emotional well-being is at a lower level (Bluth et al., 2018).

Bluth and his partners (2018) showed that older adolescents had lower self-compassion levels than younger or adolescents of all ages. Among older adolescents, self-compassion had a more significant protective effect on stress for boys than for girls. In addition, older adolescents with low and moderate self-esteem had higher depressive symptoms than those with high self-esteem. These results may inform for whom and at what age self-compassion interventions can be applied to maintain and protect emotional well-being (Bluth et al., 2018). 
Research by Yarnell and Neff (2013) on adolescents' well-being and ability to express their needs has shown that self-compassion is an appropriate means of highlighting their needs. In fact, it seems to help adopt a more authentic attitude from them.

According to Bluth, Mullarkey and Lathren (2018), self-compassion was positively correlated with curiosity/exploration and resilience. This relationship was stronger between boys than girls. In addition, self-compassion is associated with both resilience and curiosity/exploration at all ages throughout adolescence. Consequently, interventions that cultivate adolescent self-compassion can enhance resilience and curiosity/exploration by offering new and healthy ways to address these challenges that lead to improved emotional well-being (Bluth et al., 2018).

Also of interest are the studies by Jativa and Cerezo (2014) as well as Jiang and her colleagues (2016) that bring school bullying to the forefront and link it to the benefits of self-compassion. Specifically, Jativa and Cerezo (2014) showed that self-compassion plays a mediating role in the relationship between victimization and psychological adjustment. It is also associated with reduced levels of internalization in adolescents who reported falling victim to school bullying. Similar results emerged from a study by Jiang et al. (2016), which looked at the protective role of self-compassion in adolescents whom their peers have bullied.

\section{Intervention programs for teenagers}

Muris and Meesters (2014) have highlighted the potential usefulness of self-compassion interventions as a method of resisting the formation of negative self-conscious emotions and cognitive patterns, which are associated with the development of anxiety and depression in adolescence.

A study by Bluth, Roberson and Gaylord (2015) investigated the effects of a mindfulness intervention on emotional well-being in a sample of adolescents. Progress between pre-education and post-education is associated with improvements in consciousness, self-compassion, stress and life satisfaction.

Bluth and Eisenlohr-Moul (2017) conducted a small-scale study of an 8-week group self-compassion program for adolescents with a 6-week follow-up period. They found that participants' perceived stress levels were significantly reduced after the intervention and during the intervention. Resilience was significantly increased during follow-up, and gratitude and curiosity were significantly increased after intervention and follow-up. There was also a non-significant reduction in anxiety and depression symptoms after the intervention and during follow-up.

Similarly, Bluth and his colleagues (2017), in a small-scale 6-week self-compassion pilot program for non-clinical adolescents, found that those who completed the program reported increased levels of self-compassion and life satisfaction and significantly lower levels of depression in the control team. Mindfulness and self-compassion were both found to be predictors of lower levels of anxiety, depression, perceived stress and low mood in adolescents in the intervention group (Bluth et al., 2017). Both consciousness skills and skills seem to be prognostic 
factors of well-being (Baer et al., 2012).

Overall, research has shown that teaching people how to behave more compassionately when in a difficult situation has significant benefits in terms of mental well-being. Along with the increase in self-compassion, there was a significant increase in life satisfaction and subjective happiness. The latter means that the increase in self-compassion changes the way one evaluates both life satisfaction and personal happiness, such as has been observed in previous research (Neely et al., 2009; Seligowski et al., 2014; Van Dam et al., 2011; Wei et al., 2011). The results also showed that self-compassion increases positive emotions and reduces negative ones. It reduces the symptoms of depression, anxiety, and stress (Choi et al., 2014; Leary et al., 2007).

\section{The current study}

In the Greek data but also in the international research data, there are no self-compassion interventions for children and adolescents. However, the encouraging results of self-compassion interventions in adults and the articles on the association of self-compassion with high levels of well-being and low levels of psychopathology in adolescents created the need for such programs.

Utilizing the results of the programs that have been conducted in the Greek population in the previous years (Karakasidou \& Stalikas, 2017) and after the necessary improvements, the program was adapted so that it can be implemented in a younger population, children aged $8-11$. The purpose of the study was to investigate the effectiveness of the self-compassion program in children. Hence, this study aims to test the effectiveness of a self-compassion intervention in children from Greece, the effect of self-compassion on increasing the levels of positive emotions and resilience, reducing the levels of negative emotions and stress as a condition and characteristic, and reducing self-criticism, isolation, and excessive identification.

\section{Research questions}

Is a 4-week self-compassion program effective in decreasing self-criticism levels, isolation levels, over-identification levels, negative emotion rates, state anxiety levels and trait anxiety levels on a group of children aged 8 - 11 years old?

Is a 4-week self-compassion program effective in increasing self-kindness levels, common humanity levels, mindfulness levels, psychological resilience rate and positive emotions rates on a group of children aged 8 - 11 years old?

\section{Method}

\section{Participants}

A total number of sixteen individuals participated in the current study. The participants $(N=16)$ were 8 boys $(M=9.25, S D=1.04)$ and 8 girls $(M=9.50$, $S D=.76)$ with an age range of $8-11$ years old $\left(N=16, M_{\text {age }}=9.63\right)$. The children were randomly divided into the intervention group and the control group before the commencement of the intervention. The researchers used the method of snowball sampling. Participants were recruited through an advert on social 
media one month before the intervention. Sixteen responded positively and gave their consent to participate in the experiment. The criteria for joining the research were the Greek language and the current residence in Santorini.

The intervention lasted four weeks. During the intervention, the experimental group was taught self-compassion exercises with meetings twice a week for an hour and a half. At the same time, in the control condition, there was no intervention. The independent variable was the intervention of increasing self-compassion. The dependent variables were kindness, common humanity, mindfulness, self-criticism, isolation, over-identification, positive and negative affect, state and trait anxiety (see Figure 1).

All participants completed four self-report questionnaires one week before the intervention and after the last meeting. All questionnaires are weighted and adapted to the Greek population and can be administered to children of this age.

\section{Materials}

\section{Self-Compassion Scale for Children (SCS-Y)}

The Neff Self-Compassion Scale (2003b) was used to measure children's self-compassion, the children's edition (Neff, 2020), which has been translated into Greek and weighted in the Greek population (Karakasidou et al., 2021).

The scale for children assesses the level of self-compassion through 17 self-report statements on a 5-point Likert scale (1-almost never, 5-almost always). Higher scores also indicate higher levels of self-compassion (Neff, 2003b).

All negative aspects were reverse-scored, and then a total self-compassion score was calculated by taking a mean of all items. The SCS-SF has good psychometric properties, with high internal consistency and an almost perfect correlation with the long form of the SCS (Raes et al., 2011). Higher scores correspond to higher levels of self-compassion.

\section{Short Resistance Scale (BRS)}

The resilience of children with the Short Resilience Scale of Smith, and his

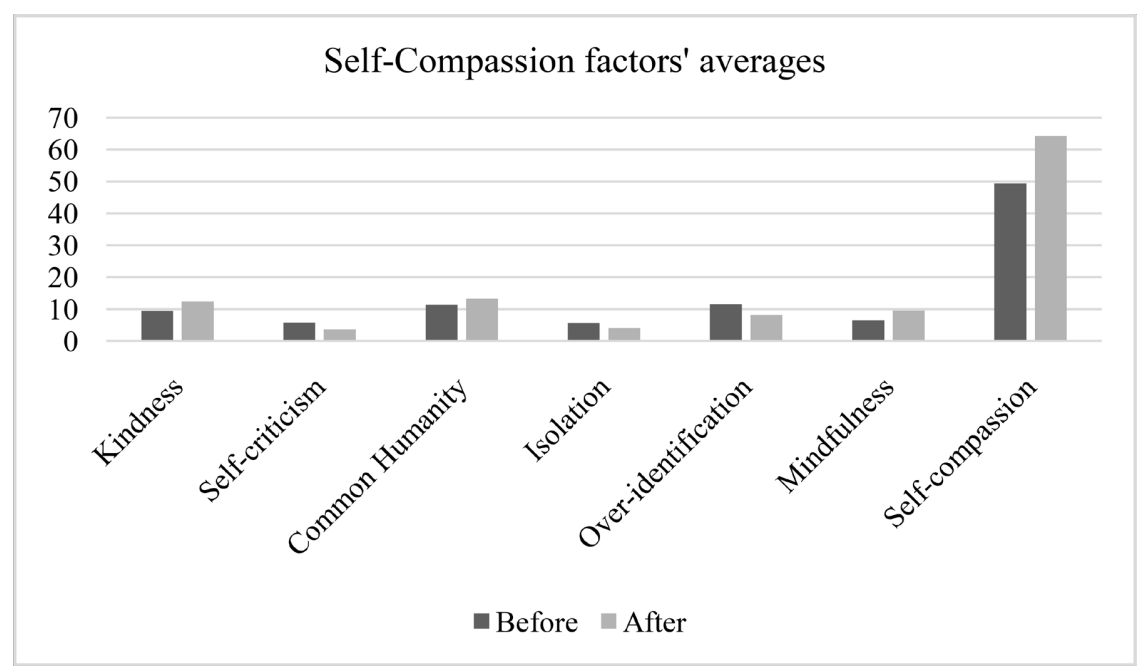

Figure 1. Self-compassion factors' levels before and after intervention in the experiment group. 
partners (2008) has been weighted in the Greek population (Kyriazos, Stalikas, Prassa, Galanakis et al., 2018) was also examined. It contains six elements that measure the ability to recover from stress and difficulties. Items are rated on a 5-point Likert scale ranging from Strongly Disagree (1) to Strongly Agree (5).

\section{Positive and negative experience scale (SPANE-12)}

The scale of positive and negative experience (SPANE) (Diener et al., 2009), which has been weighted in the Greek population (Kyriazos, Stalika, Prassa, \& Giotsidis, 2018), is a short scale of 12 items, with six items dedicated to positive experiences and six items designed to evaluate negative experiences. In addition, the scale can measure emotions such as physical pleasure, involvement, interest, pain and boredom.

The positive and negative experience scale gives three scores: the overall balance of influence score (SPANE-B) and the positive and negative emotion scales, SPANE-P and SPANE-N. The latest scale scores range from 6 to 30, with higher numbers representing higher positive or negative emotions. These ratings show the tendency of the individual to feel and recognize the emotions in himself. The Influence Balance Scale (SPANE-B) is a measure of the balance between positive and negative emotions, and the resulting score can range from -24 (unhappy) to 24 (happiest).

SPANE performs well in terms of reliability and convergent validity with other measures of emotion, wellness, happiness and life satisfaction. The three subcategories showed high Cronbach's alpha and time stability for one month: SPANE-P .87, .62; SPANE-N, .81, .63; and SPANE-B, .89, .68 (Diener et al., 2009).

\section{Stress Scale (Self-Assessment) (STAI)}

The State-Trait Anxiety Inventory (STAI) scale is a widely used measure (Spielberger et al., 1983), which has been weighted in the Greek population by Psychountaki, Zervas, Karteroliotis, \& Spielberger (2003).

It separates stress as a state and stress as a trait. It consists of two separate subscales of self-report and measures the current state of anxiety (state anxiety). In general, stress is an element of the person's personality (trait anxiety) who completes the form.

Each sub-scale of the questionnaire consists of 20 sentences-answers graded on a Likert scale of four levels $(1,2,3,4)$ with a possible score from 20 to 80 points. The range of responses ranges from none at all (0), somewhat (1), moderate (2), too much (3), to the subscale that considers stress as a condition and almost never (0), sometimes (1), often (2), almost always (3) for the subscale that examines stress as a personality trait. In the end, the total of the accumulated points of each sub-scale is calculated separately and in combination with the two sub-scales. Higher scores indicate more stress.

The internal cohesion coefficients for the scale range from .86 to .95 . Test-toreliability ratios ranged from .65 to .75 over two months (Spielberger et al., 1983).

\section{Procedure}


The present study was conducted following the ethics from the Greek Psychological Society. First, the researchers provided the participants and their parents a briefing on the intervention process. They were informed that the participation was anonymous and voluntary and that they could withdraw at any time. The parents provided their written consent, and the participants provided their oral consent. Then, the researchers divided them into two groups, the experimental group and the control group.

Participants were initially asked to answer a demographic questionnaire and four self-reported questionnaires one week before the intervention's start. The intervention lasted four weeks. Due to the occurrence of the COVID-19 pandemic, the program was carried out online. The group met twice a week online. The meetings lasted an hour and a half. The intervention aimed to familiarize participants with positive psychological concepts, emphasizing self-compassion. Each session focused on a specific topic related to cultivating self-compassion. All meetings were co-led by two trainers (two first authors).

The researchers utilized the protocol of an already established self-compassion program, led by Karakasidou and Stalikas (2017), whose aim was to investigate the effectiveness of a self-compassion intervention and whether a self-compassion intervention can predict changes in positive and negative affect, symptoms of depression, anxiety, and stress, life satisfaction and subjective happiness. After the necessary improvements, the program was adapted so that it could be implemented in a younger population, children aged 8 - 11 .

Each week was dedicated to a specific topic. The first week focused on familiarizing the participants with the concepts of positive psychology that they would use, self-compassion, positive emotions and psychological resilience. During the second week, the children focused on training to self-kindness meditation and recognizing emotions. During the third week, the trainers facilitated participants to develop a "compassionate inner voice" through role-playings and painting. In week 4 , the participants exercised skills to cope with challenging situations and deal with difficult emotions effectively. The last meeting focused on more general issues, such as relating with positive aspects of oneself and creating a self-compassion motto. They also provided feedback regarding their experience. One week after the end of the intervention, the participants completed the questionnaires.

\section{Results}

The data collected from the pilot program were analyzed with the statistical package SPSS, version 26. Initially, it was checked whether there were differences between the control group and the intervention group in any demographics or measurements before the intervention. The analyses showed no statistically significant differences in the variables, so the two groups can be considered equal.

Then, in order to answer the first research question, whether self-compassion intervention effectively reduces self-criticism, isolation, over-identification, neg- 
ative emotion, state anxiety and trait anxiety, a series of paired-samples t-test to determine if there were differences before and after the intervention in both the control group and the intervention group. The results showed a statistically significant decrease in self-criticism $(t=9.38, p<.001)$, isolation $(t=5.61, p$ $=.001)$, over-identification or avoidance $(t=8.04, p<.001)$, state anxiety $(t=$ $14.92, p<.001)$ and trait anxiety $(t=5.61, p=.001)$. However, the negative emotions did not show a statistically significant decrease $(t=1.53, p=.17)$. As expected, the control group did not show statistically significant differences.

Regarding the second research question, whether the self-compassion intervention effectively increases self-kindness, common humanity, mindfulness, mental resilience and positive emotions, the same procedure was followed, i.e. a series of paired-samples t-test was performed to determine if there were differences before and after the intervention in both the control group and the intervention group. The results showed a statistically significant increase in self-goodness $(t=-9.17, p<.001)$, common humanity $(t=-8.28, p<.001)$, mindfulness $(t=-9.17, p<.001)$, mental resilience $(t=-81, p<.001)$ and positive emotions $(t=-8.76, p<.001)$. As expected, the control group did not show statistically significant differences.

In addition, in order to determine whether the intervention group reported improvements in the levels of the variables in relation to the control group, the method of Variance Analysis was performed, namely that of repeated measures [Group: VS Control Intervention $\times 2$ Time: Before VS After]. The results showed that there was a statistically significant interaction between time (before the start of the intervention and after its end) and the group (intervention-control) (Table 1).

In addition, a series of t-tests for independent samples showed a statistically significant difference between the intervention group and the control group, with the former reporting higher levels of self-efficacy $[t(14)=4.57, p<.001]$, common humanity $[t(14)=4.32, p<.001]$, of consciousness $[t(14)=4.47, p$ $=.001]$, of mental resilience $[t(14)=2.22, p=.043]$, of positive emotions $[t(14)$ $=2.48, p=.027)$ in relation to the second. The results also showed lower levels of self-criticism $[t(14)=-4.41, p<.001]$, isolation $[t(14)=-3.56, p=.003]$, excessive identification or avoidance $[t(14)=-5.06, p=.000]$, stress as a condition $[t$ $(14=-4.704, p=.000]$ and stress as a characteristic $[t(14)=-2.20, p$ $=.045]$. However the results did not show statistics significantly lower negative emotions $[t(14)=-0.05, p=.958]$, compared to the control group.

\section{Discussion}

This study aimed to investigate the effect of a four-week self-compassion intervention for children aged 8 - 11 years of age. We hypothesized that attending a self-compassion program would help these children change how they relate to themselves, empower them, and effectively reduce self-criticism, isolation, and over-identification, negative emotion, state anxiety, trait anxiety, and would 
Table 1. (Group) × 2 (Time) Analysis of variance of repeated measurements.

\begin{tabular}{|c|c|c|c|c|c|c|}
\hline & \multicolumn{2}{|c|}{ Experiment Group } & \multicolumn{2}{|c|}{ Control Group } & \multirow[b]{2}{*}{$F$} & \multirow[b]{2}{*}{$\mathrm{Eta}^{2}$} \\
\hline & $\begin{array}{l}\text { Before } \\
M(S D)\end{array}$ & $\begin{array}{c}\text { After } \\
M(S D)\end{array}$ & $\begin{array}{l}\text { Before } \\
M(S D)\end{array}$ & $\begin{array}{c}\text { After } \\
M(S D)\end{array}$ & & \\
\hline Self-compassion & $\begin{array}{l}49.38 \\
(3.42)\end{array}$ & $\begin{array}{l}64.25 \\
(4.06)\end{array}$ & $\begin{array}{l}45.75 \\
(3.88)\end{array}$ & $\begin{array}{l}44.50 \\
(2.88)\end{array}$ & 136.882 & .907 \\
\hline Kindness & $\begin{array}{c}9.38 \\
(1.93)\end{array}$ & $\begin{array}{l}12.38 \\
(1.77)\end{array}$ & $\begin{array}{c}8.88 \\
(1.64)\end{array}$ & $\begin{array}{c}8.63 \\
(1.51)\end{array}$ & 78.867 & .849 \\
\hline Self-criticism & $\begin{array}{c}5.75 \\
(1.04)\end{array}$ & $\begin{array}{c}3.63 \\
(0.92)\end{array}$ & $\begin{array}{c}6.5 \\
(1.20)\end{array}$ & $\begin{array}{c}6.37 \\
(1.51)\end{array}$ & 28.903 & .674 \\
\hline Common Humanity & $\begin{array}{l}11.38 \\
(1.41)\end{array}$ & $\begin{array}{l}13.25 \\
(1.39)\end{array}$ & $\begin{array}{l}10.63 \\
(1.06)\end{array}$ & $\begin{array}{l}10.25 \\
(1.39)\end{array}$ & 26.372 & .653 \\
\hline Isolation & $\begin{array}{c}5.63 \\
(1.19)\end{array}$ & $\begin{array}{c}4.13 \\
(1.13)\end{array}$ & $\begin{array}{c}6.13 \\
(1.13)\end{array}$ & $\begin{array}{c}6.5 \\
(1.51)\end{array}$ & 16.579 & .542 \\
\hline Mindfulness & $\begin{array}{c}6.5 \\
(1.31)\end{array}$ & $\begin{array}{c}9.5 \\
(1.51)\end{array}$ & $\begin{array}{c}5.5 \\
(1.85)\end{array}$ & $\begin{array}{c}5.75 \\
(1.83)\end{array}$ & 56.467 & .801 \\
\hline Over-identification & $\begin{array}{c}11.5 \\
(1.77)\end{array}$ & $\begin{array}{c}8.13 \\
(1.36)\end{array}$ & $\begin{array}{l}11.63 \\
(1.85)\end{array}$ & $\begin{array}{c}12 \\
(1.69)\end{array}$ & 67.021 & .827 \\
\hline Resilience & $\begin{array}{l}19.75 \\
(2.61)\end{array}$ & $\begin{array}{l}22.38 \\
(2.20)\end{array}$ & $\begin{array}{l}20.13 \\
(1.89)\end{array}$ & $\begin{array}{l}20.00 \\
(2.07)\end{array}$ & 48.400 & \\
\hline Positive affect & $\begin{array}{l}19.88 \\
(4.32)\end{array}$ & $\begin{array}{l}25.38 \\
(3.46)\end{array}$ & $\begin{array}{l}21.88 \\
(3.76)\end{array}$ & $\begin{array}{l}21.13 \\
(3.40)\end{array}$ & 44.192 & \\
\hline Negative affect & $\begin{array}{l}17.25 \\
(4.74)\end{array}$ & $\begin{array}{c}17 \\
(4.90)\end{array}$ & $\begin{array}{c}16.5 \\
(4.84)\end{array}$ & $\begin{array}{l}17.13 \\
(4.45)\end{array}$ & .803 & \\
\hline State Anxiety & $\begin{array}{l}31.04 \\
(4.06)\end{array}$ & $\begin{array}{l}24.63 \\
(3.96)\end{array}$ & $\begin{array}{l}32.13 \\
(3.18)\end{array}$ & $\begin{array}{l}33.38 \\
(3.46)\end{array}$ & 91.751 & \\
\hline Trait Anxiety & $\begin{array}{l}37.13 \\
(1.96)\end{array}$ & $\begin{array}{l}34.13 \\
(2.17)\end{array}$ & $\begin{array}{l}37.24 \\
(1.77)\end{array}$ & $\begin{array}{l}36.25 \\
(1.67)\end{array}$ & 6.950 & .332 \\
\hline
\end{tabular}

increase self-kindness, common humanity, mindfulness, psychological resilience and positive emotions. We compared before and after ratings in the control and the intervention group.

Regarding the first research question, the results showed that a self-compassion intervention seems to help reduce state anxiety, trait anxiety, isolation and over-identification, which means that self-compassion is a useful tool for this age group.

With regards to the second research hypothesis, the research results showed that teaching children how to behave with more compassion towards themselves when they are in a difficult situation through a four-week program has significant benefits in indicators of mental well-being. Along with the increase in self-compassion, there was a significant increase in self-kindness, common humanity, mindfulness, mental resilience and positive emotions.

In addition, research results show that this self-compassion program leads to a 
statistically significant increase in levels of positive emotions (Heffernan et al., 2010; Hollis-Walker \& Colosimo, 2011; Neff, Rude, \& Kirkpatrick, 2007). Cultivating self-compassion can be related to how people perceive and evaluate their lives and give meaning to their everyday situations. Positive emotions help people recognize the positive elements in their daily lives, change their focus from negative to positive, and broaden their thinking (Fredrickson, 2001; Fredrickson \& Branigan, 2005).

Along with increasing levels of positive emotions, the results of this study showed that cultivating self-compassion can have positive effects on increasing levels of mental resilience (see Figure 2). Due to the lack of studies examining the relationship between self-compassion and resilience, there is insufficient evidence to support this finding. However, since self-compassion is by definition a more functional way of relating to ourselves in difficult situations, it seems that it can be positively related to resilience (Neff \& McGehee, 2010). It is imperative to emphasize that building resilience is a complex process, and it is necessary to combine a variety of interventions to enable its cultivation and conservation (Southwick et al., 2011).

Self-compassion, then, is an important concept, with useful results in maintaining the balance of mental health of the individual, and the creation of a program that teaches children how to be more self-compassion creates new avenues of mental health and well-being, especially for this age group. Self-compassion can be a different path to positivity by reducing stress levels, isolation, over-identification and self-criticism, and increasing well-being-related variables such as positive emotions. The purpose of self-compassion is to listen to the pain, integrate it into a universal context, recognize behaviours that do not work for the benefit of one's health, and not simply hasten relief from regrets and guilt

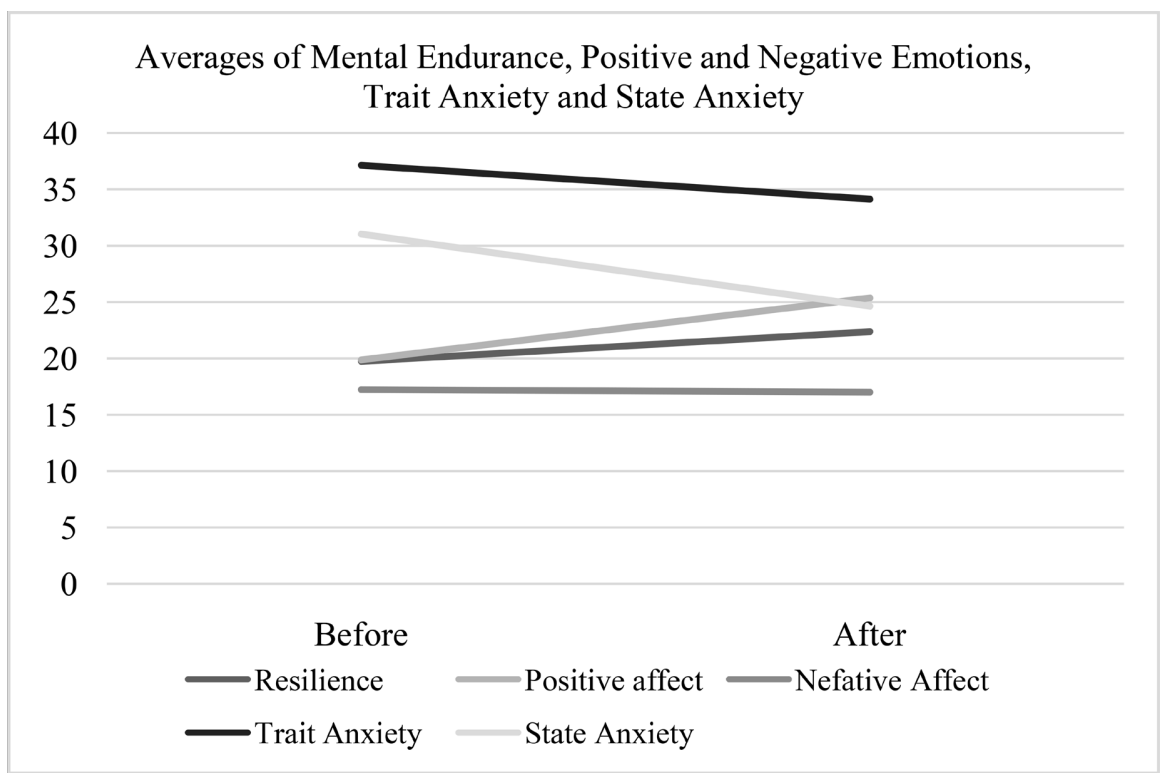

Figure 2. Levels of mental resilience, positive emotions, negative emotions, trait anxiety and state anxiety before and after the intervention in the experiment group. 
and trap people in a vicious circle of maladaptation, thoughts and attitudes. This research shows that self-compassion as a way of life, a skill, and learned behaviour is useful for achieving psychological well-being.

One of the most important findings of the present study is that self-compassion can be taught to children. Also, it is worth mentioning that important directions for improvements were created through the participants' feedback. These changes concern the meetings' and the program's duration and the experiential exercises and homework enrichment.

Children and adolescents can relate in a more compassionate approach to themselves, enhance their well-being, and manage the challenges they face so that they can cope with them both emotionally and practically. Through different ways of relating to oneself, children will be able to listen to their needs, increase their well-being levels (Neff, 2011; Zessin et al., 2015) and reduce the symptoms of anxiety (stress) (Neff et al., 2005; Neff, Kirkpatrick, \& Rude, 2007). This whole process of change can also shape how they give meaning and value to themselves and their relationships. Through this program of self-compassion, it seems that the younger population may learn to use practices of mindfulness and accept challenging experiences in the here and now while at the same time learning to be actively involved in behaviours of kindness to themselves and self-care.

Overall, the findings of this study provided preliminary support for self-compassion as a protective psychological factor for adolescents, improving stress responses and psychopathological symptoms, and increasing positive emotional well-being. Recognizing both the lack of self-compassion programs in children and adolescents, as well as the need to address emotional challenges at this critical developmental stage, this study helped enhance the mental health of this age group. Recognizing the lack of self-compassion programs in children and adolescents and the need to address emotional challenges at this critical developmental stage, it was found that this program would be of particular interest to children. Considering the flourishing of the concept of self-compassion in combination with the absence of research data, which highlight the effectiveness of intervention programs in children, the need arose to conduct research in the Greek population to create a training program in self-compassion and its implementation in children. A large number of researchers have turned their attention to exploring the concept of self-compassion, looking for the benefits that one can obtain by utilizing it in various areas of one's life. Expanding the horizons of our knowledge regarding this concept creates the need to connect theory with practical application. Creating programs to educate people to be compassionate towards themselves is important in expanding scientific knowledge and applying theory in everyday practice. Cultivating self-compassion can provide a gateway through which children and adolescents can enhance their emotional well-being and reduce the symptoms of anxiety, stress and depression. Through a self-compassion program, children may learn to use mindfulness practices and 
accept challenging experiences here and now while learning to be actively involved in self-care and self-care attitudes.

Summarizing the results of this research, it can be said that the Self-Compassion Program worked positively for these children. Participation in this program seems to have strengthened their self-compassion and, at the same time, increased the levels of positive emotions and mental resilience. Furthermore, the results showed that participation in the program led to a reduction in self-criticism, isolation, over-identification, negative emotions, state anxiety and trait anxiety. These findings seem to be consistent with the results of previous research on intervention programs (Albertson, et al., 2015; Karakasidou \& Stalikas 2017; Germer \& Neff, 2013). They are also more generally consistent with the literature that emphasizes the benefits of self-compassion in mental health (Gilbert \& Irons, 2004; Neff \& Costigan, 2014).

\section{Gaps and Limitations}

The limitations of this study provide important guidance for future research. More specifically, the sample consisted exclusively of children aged $8-11$, so the results cannot be generalized to populations with other characteristics (e.g. different national and cultural backgrounds), which could be the object of study of subsequent research. In addition, the intervention was performed on children living in Greece, so no conclusions can be drawn regarding the geographical area of residence, which may vary the results.

The current research was conducted using self-report scales, so the usual variation of the method may have affected the results (Podsakoff et al., 2003). It would be interesting to use a combination of quantitative and qualitative methods to explore this concept holistically. The interest of future research could be focused on much larger samples or different age groups but also to find application in specific clinical populations, e.g. children with generalized anxiety disorder, etc., if it is associated with a reduction in stress levels.

The implementation of the intervention online may be a limitation but also a strength. Online interventions are a new way of intervention. Therefore, there is not much research showing who can benefit from this modality. Moreover, due to online participation, only people familiar with the use of technology could participate. As a result, there is a limit regarding generalization to the general population. However, due to the pandemic, there was a need to adjust the program. This flexibility allowed participants from different locations to engage in the program. It is more than clear that further research is required to investigate the effectiveness of online interventions.

Overall, the results of this study show that this program has significant benefits for this population. We must remember that childhood is a period with many developmental, emotional, social, and psychological challenges, especially within the school environment, where children coexist and interact daily and cope and manage various stimuli and difficulties. Therefore, it would be very 
useful for children to be trained in exercises to cultivate and strengthen self-compassion, with the ultimate goal of managing the daily challenges that arise both intra-individually and diatomically.

\section{Contribution to Scientific Knowledge and Therapeutic Practice}

The research findings show the effectiveness of an intervention program, emphasizing the benefits of self-compassion in the mental health of children and adolescents. The fact that self-compassion is a skill that can be learnt opens new avenues in positive interventions, giving another dimension to the relationship between theory and practice. The possibility of education is an important issue in research as it goes one step further from theory giving it substance on a practical level. It is also an optimistic perspective, enabling people to feel that they can improve their daily lives by using life tools created through scientifically detailed data.

Knowing that self-compassion is a skill that can be learnt, we add another variable to the list of positive psychology concepts people can train in. Still, the exercises for learning could enrich and reinforce other positive interventions, such as programs related to the positive elements of character and the concept of consciousness.

In addition, the positive effects of the intervention on the individual's mental health, which are reflected in high levels of well-being indicators and low levels of psychopathological symptoms, give impetus to the field of psychotherapy, consolidating the value of self-compassion, as well as the need for education.

The contribution of this dissertation to research moves on many levels. Research on self-compassion is under development, with more and more researchers exploring this concept's role in various fields. However, the field of programming has been little studied in a structured and systematic way both nationally and globally. The importance of her research lies in the fact that for the first time, the implementation of a structured training program for people to be compassionate towards themselves was studied, using quantitative data to check the effectiveness of both the main variable and mental health factors and indicators.

\section{Conclusion}

Self-compassion reminds the individual of the way they should relate to themselves in times of crisis. Learning to stand with understanding, respect, acceptance and love for them not only helps to strengthen mental and physical health but also affects relationships with others.

Summarizing the findings of the study of this work, we need to refer to the importance of expanding our knowledge both in this sense and in the methodology of controlling the effectiveness of positive interventions. This study, which is one of the few studies worldwide on self-compassion education programs in children, found that self-compassion is learnt and that participating in 
a self-compassion program increases mental resilience and positive emotions while reducing stress as a feature and as a condition.

By training the individual to be more compassionate towards himself, he learns to relate in a different way to all aspects of himself and to become better. Self-compassion is an attitude of life, a process of constructing meaning and interpreting reality and functions as a factor in developing and strengthening the relationship with oneself and others.

\section{Fund}

This research is co-financed by Greece and the European Union (European Social Fund-ESF) through the Operational Programme "Human Resources Development, Education and Lifelong Learning" in the context of the project "Reinforcement of Postdoctoral Researchers-2 ${ }^{\text {nd }}$ Cycle" (MIS-5033021), implemented by the State Scholarships Foundation (IKY).

\section{Conflicts of Interest}

The authors declare no conflicts of interest regarding the publication of this paper.

\section{References}

Albertson, E. R., Neff, K. D., \& Dill-Shackleford, K. E. (2015). Self-Compassion and Body Dissatisfaction in Women: A Randomized Controlled Trial of a Brief Meditation Intervention. Mindfulness, 6, 444-454. https://doi.org/10.1007/s12671-014-0277-3

Baer, R. A., Lykins, E. L., \& Peters, J. R. (2012). Mindfulness and Self-Compassion as Predictors of Psychological Well-Being in Long-Term Meditators and Matched Nonmeditators. The Journal of Positive Psychology, 7, 230-238.

https://doi.org/10.1080/17439760.2012.674548

Barnard, L. K., \& Curry, J. F. (2011). Self-Compassion: Conceptualizations, Correlates, \& Interventions. Review of General Psychology, 15, 289-303.

https://doi.org/10.1037/a0025754

Bluth, K., \& Blanton, P. W. (2015). The Influence of Self-Compassion on Emotional Well-Being among Early and Older Adolescent Males and Females. The Journal of Positive Psychology, 10, 219-230. https://doi.org/10.1080/17439760.2014.936967

Bluth, K., \& Eisenlohr-Moul, T. A. (2017). Response to a Mindful Self-Compassion Intervention in Teens: A Within-Person Association of Mindfulness, Self-Compassion, and Emotional Well-Being Outcomes. Journal of Adolescence, 57, 108-118.

https://doi.org/10.1016/j.adolescence.2017.04.001

Bluth, K., Campo, R. A., Futch, W. S., \& Gaylord, S. A. (2017). Age and Gender Differences in the Associations of Self-Compassion and Emotional Well-Being in a Large Adolescent Sample. Journal of Youth and Adolescence, 46, 840-853.

https://doi.org/10.1007/s10964-016-0567-2

Bluth, K., Mullarkey, M., \& Lathren, C. (2018). Self-Compassion: A Potential Path to Adolescent Resilience and Positive Exploration. Journal of Child and Family Studies, 27, 3037-3047. https://doi.org/10.1007/s10826-018-1125-1

Bluth, K., Roberson, P. N., \& Gaylord, S. A. (2015). A Pilot Study of a Mindfulness Intervention for Adolescents and the Potential Role of Self-Compassion in Reducing Stress. 
Explore, 11, 292-295. https://doi.org/10.1016/j.explore.2015.04.005

Campos, D., Cebolla, A., Quero, S., Bretón-López, J., Botella, C., Soler, J. et al. (2015). Meditation and Happiness: Mindfulness and Self-Compassion May Mediate the Meditation-Happiness Relationship. Personality and Individual Differences, 93, 80-85. https://doi.org/10.1016/j.paid.2015.08.040

Choi, Y., Lee, D., \& Lee, H. (2014). The Effect of Self-Compassion on Emotions When Experiencing a Sense of Inferiority across Comparison Situations. Procedia-Social and Behavioral Sciences, 114, 949-953. https://doi.org/10.1016/j.sbspro.2013.12.813

Diener, E., Wirtz, D., Tov, W., Kim-Prieto, C., Choi, D., Oishi, S., \& Biswas-Diener, R. (2009). New Well-Being Measures: Short Scales to Assess Flourishing and Positive and Negative Feelings. Social Indicators Research, 97, 143-156.

https://doi.org/10.1007/s11205-009-9493-y

Fredrickson, B. (2001). The Role of Positive Emotions in Positive Psychology: The Broaden-and-Build Theory of Positive Emotions. American Psychologist, 56, 218-226. https://doi.org/10.1037/0003-066X.56.3.218

Fredrickson, B., \& Branigan, C. (2005). Positive Emotions Broaden the Scope of Attention and Thought-Action Repertoires. Cognition \& Emotion, 19, 313-332.

https://doi.org/10.1080/02699930441000238

Germer, C. K., \& Neff, K. D. (2013). Self-Compassion in Clinical Practice. Journal of Clinical Psychology, 69, 856-867. https://doi.org/10.1002/jclp.22021

Gilbert, P., \& Irons, C. (2004). A Pilot Exploration of the Use of Compassionate Images in a Group of Self-Critical People. Memory, 12, 507-516.

https://doi.org/10.1080/09658210444000115

Heffernan, M., Quinn Griffin, M. T., McNulty, S. R., \& Fitzpatrick, J. J. (2010). Self-Compassion and Emotional Intelligence in Nurses. International Journal of Nursing Practice, 16, 366-373. https://doi.org/10.1111/j.1440-172X.2010.01853.x

Hollis-Walker, L., \& Colosimo, K. (2011). Mindfulness, Self-Compassion, and Happiness in Non-Meditators: A Theoretical and Empirical Examination. Personality and Individual Differences, 50, 222-227. https://doi.org/10.1016/j.paid.2010.09.033

Jativa, R., \& Cerezo, M. (2014). The Mediating Role of Self-Compassion in the Relationship between Victimization and Psychological Maladjustment in a Sample of Adolescents. Child Abuse \& Neglect, 38, 1180-1190. https://doi.org/10.1016/j.chiabu.2014.04.005

Jiang, Y., You, J., Hou, Y., Du, C., Lin, M., Zheng, X., \& Ma, C. (2016). Buffering the Effects of Peer Victimization on Adolescent Non-Suicidal Self-Injury: The Role of Self-Compassion and Family Cohesion. Journal of Adolescence, 53, 107-115. https://doi.org/10.1016/j.adolescence.2016.09.005

Karakasidou, E., \& Stalikas, A. (2017). Empowering the Battered Women: The Effectiveness of a Self-Compassion Program. Psychology, 8, 2200.

https://doi.org/10.4236/psych.2017.813140

Karakasidou, E., Raftopoulou, G., Pezirkianidis, C., \& Stalikas, A. (2021). Validity, Reliability and Factorial Structure of the Self Compassion Scale-Youth Version in the Greek Population. Psychology, 12, 536-553. https://doi.org/10.4236/psych.2021.124033

Kyriazos, T., Stalikas, A., Prassa, K., \& Yotsidi, V. (2018). A 3-Faced Construct Validation and a Bifactor Subjective Well-Being Model Using the Scale of Positive and Negative Experience, Greek Version. Psychology, 9, 1143-1175.

https://doi.org/10.4236/psych.2018.95071

Kyriazos, T., Stalikas, A., Prassa, K., Galanakis, M., Yotsidi, V., \& Lakioti, A. (2018). Psy- 
chometric Evidence of the Brief Resilience Scale (BRS) and Modeling Distinctiveness of Resilience from Depression and Stress. Psychology, 9, 1828-1857.

https://doi.org/10.4236/psych.2018.97107

Leary, M. R., Tate, E. B., Adams, C. E., Allen, A. B., \& Hancock, J. (2007). Self-Compassion and Reactions to Unpleasant Self-Relevant Events: The Implications of Treating Oneself Kindly. Journal of Personality and Social Psychology, 92, 887-904.

https://doi.org/10.1037/0022-3514.92.5.887

MacBeth, A., \& Gumley, A. (2012). Exploring Compassion: A Meta-Analysis of the Association between Self-Compassion and Psychopathology. Clinical Psychological Review, 32, 545-552. https://doi.org/10.1016/j.cpr.2012.06.003

Mosewich, A. D., Kowalski, K. C., Sabiston, C. M., Sedgwick, W. A., \& Tracy, J. L. (2011). Self-Compassion: A Potential Resource for Young Women Athletes. Journal of Sport and Exercise Psychology, 33, 103-123. https://doi.org/10.1123/jsep.33.1.103

Muris, P., \& Meesters, C. (2014). Small or Big in the Eyes of the Other: On the Developmental Psychopathology of Self-Conscious Emotions as Shame, Guilt, and Pride. Clinical Child and Family Psychology Review, 17, 19-40. https://doi.org/10.1007/s10567-013-0137-Z

Neely, M. E., Schallert, D. L., Mohammed, S. S., Roberts, R. M., \& Chen, Y.-J. (2009). Self-Kindness When Facing Stress: The Role of Self-Compassion, Goal Regulation, and Support in College Students' Well-Being. Motivation and Emotion, 33, 88-97. https://doi.org/10.1007/s11031-008-9119-8

Neff, K. (2003a). The Development and Validation of a Scale to Measure Self-Compassion. Self and Identity, 2, 223-250. https://doi.org/10.1080/15298860309027

Neff, K. (2003b). Self-Compassion: An Alternative Conceptualization of a Healthy Attitude toward Oneself. Self and Identity, 2, 85-101. https://doi.org/10.1080/15298860309032

Neff, K. (2011). Self-Compassion, Self-Esteem, and Well-Being. Social and Personality Psychology Compass, 5, 1-12. https://doi.org/10.1111/j.1751-9004.2010.00330.x

Neff, K. (2020). What Self-Compassion Is Not: Self-Esteem, Self-Pity, Indulgence. https://self-compassion.org/what-self-compassion-is-not-2

Neff, K. D., \& Costigan, A. P. (2014). Self-Compassion, Well-Being, and Happiness. Psychologie in Österreich, 2, 114-119.

Neff, K. D., \& McGee, P. (2010). Self-Compassion and Psychological Resilience among Adolescents and Young Adults. Self and Identity, 9, 225-240. https://doi.org/10.1080/15298860902979307

Neff, K. D., Hsieh, Y. P., \& Dejitterat, K. (2005). Self-Compassion, Achievement Goals, and Coping with Academic Failure. Self and Identity, 4, 263-287. https://doi.org/10.1080/13576500444000317

Neff, K. D., Kirkpatrick, K. L., \& Rude, S. S. (2007). Self-Compassion and Adaptive Psychological Functioning. Journal of Research in Personality, 41, 139-154. https://doi.org/10.1016/j.jrp.2006.03.004

Neff, K. D., Pisitsungkagarn, K., \& Hseih, Y. (2008). Self-Compassion and Self-Construal in the United States, Thailand, and Taiwan. Journal of Cross-Cultural Psychology, 39, 267-285. https://doi.org/10.1177/0022022108314544

Neff, K., Rude, S., \& Kirkpatrick, K. (2007). An Examination of Self-Compassion in Relation to Positive Psychological Functioning and Personality Traits. Journal of Research in Personality, 41, 908-916. https://doi.org/10.1016/j.jrp.2006.08.002 
Podsakoff, P. M., MacKenzie, S. B., Lee, J. Y., \& Podsakoff, N. P. (2003). Common Method Biases in Behavioral Research: A Critical Review of the Literature and Recommended Remedies. Journal of Applied Psychology, 88, 879-903. https://doi.org/10.1037/0021-9010.88.5.879

Psychountaki, M., Zervas, Y., Karteroliotis, K., \& Spielberger, C. (2003). Reliability and Validity of the Greek Version of the STAIC. European Journal of Psychological Assessment, 19, 124. https://doi.org/10.1027//1015-5759.19.2.124

Raes, F., Pommier, E., Neff, K. D., \& Van Gucht, D. (2011). Construction and Factorial Validation of a Short Form of the Self-Compassion Scale. Clinical Psychology \& Psychotherapy, 18, 250-255. https://doi.org/10.1002/cpp.702

Seligman, M. E. P., \& Csikszentmihalyi, M. (2000). Positive Psychology: An Introduction. American Psychologist, 55, 5-14. https://doi.org/10.1037/0003-066X.55.1.5

Seligowski, A., Miron, L., \& Orcutt, H. (2014). Relations among Self-Compassion, PTSD Symptoms, and Psychological Health in a Trauma-Exposed Sample. Mindfulness, 6, 1033-1041. https://doi.org/10.1007/s12671-014-0351-x

Smith, B., Dalen, J., Wiggins, K., Tooley, E., Christopher, P., \& Bernard, J. (2008). The Brief Resilience Scale: Assessing the Ability to Bounce Back. International Journal of Behavioral Medicine, 15, 194-200. https://doi.org/10.1080/10705500802222972

Southwick, S. M., Pietrzak, R. H., \& White, G. (2011). Interventions to Enhance Resilience and Resilience-Related Constructs in Adults. In S. M. Southwick, B. T. Litz, D. Charney, \& M. J. Friedman (Eds.), Resilience and Mental Health: Challenges across the Lifespan (pp. 289-306). Cambridge University Press. https://doi.org/10.1017/CBO9780511994791.022

Spielberger, C. D., Gorsuch, R. L., Lushene, R., Vagg, P. R., \& Jacobs, G. A. (1983). Manual for the State-Trait Anxiety Scale. Consulting Psychologists Press.

Stolow, D., Zuroff, D., Young, J., Karlin, R., \& Abela, J. (2016). A Prospective Examination of Self-Compassion as a Predictor of Depressive Symptoms in Children and Adolescents. Journal of Social and Clinical Psychology, 35, 1-20. https://doi.org/10.1521/jscp.2016.35.1.1

Tanaka, M., Wekerle, C., Schmuck, M., \& Paglia-Boak, A. (2011). The Linkages among Childhood Maltreatment, Adolescent Mental Health, and Self-Compassion in Child Welfare Adolescents. Child Abuse \& Neglect, 35, 887-898. https://doi.org/10.1016/j.chiabu.2011.07.003

Umphrey, L. R., \& Sherblom, J. C. (2014). The Relationship of Hope to Self-Compassion, Relational Social Skill, Communication Apprehension, and Life Satisfaction. International Journal of Wellbeing, 4, 1-18. https://doi.org/10.5502/ijw.v4i2.1

Van Dam, N. T., Sheppard, S. C., Forsyth, J. P., \& Earleywine, M. (2011). Self-Compassion Is a Better Predictor than Mindfulness of Symptom Severity and Quality of Life in Mixed Anxiety and Depression. Journal of Anxiety Disorders, 25, 123-130.

https://doi.org/10.1016/j.janxdis.2010.08.011

Wei, M., Liao, K., Ku, T., \& Shaffer, P. (2011). Attachment, Self-Compassion, Empathy, and Subjective Well-Being among College Students and Community Adults. Journal of Personality, 79, 191-221. https://doi.org/10.1111/j.1467-6494.2010.00677.x

Xavier, A., Cunha, M., \& Pinto Gouveia, J. (2015). Deliberate Self-Harm in Adolescence: the Impact of Childhood Experiences, Negative Affect and Fears of Compassion. Revista de Psicopatología y Psicología Clínica, 20, 41-49.

https://doi.org/10.5944/rppc.vol.1.num.1.2015.14407

Yang, Y., Zhang, M., \& Kou, Y. (2016). Self-Compassion and Life Satisfaction: The Me- 
diating Role of Hope. Personality and Individual Differences, 98, 91-95.

https://doi.org/10.1016/j.paid.2016.03.086

Yarnell, L. M., \& Neff, K. D. (2013). Self-Compassion, Interpersonal Conflict Resolutions, and Well-Being, Self and Identity, 12, 146-159.

https://doi.org/10.1080/15298868.2011.649545

Zabelina, D. L., \& Robinson, M. D. (2010). Creativity as Flexible Cognitive Control. Psychology of Aesthetics, Creativity, and the Arts, 4, 136-143.

https://doi.org/10.1037/a0017379

Zeller, M., Yuval, K., Nitzan-Assayag, Y., \& Bernstein, A. (2015). Self-Compassion in Recovery Following Potentially Traumatic Stress: Longitudinal Study of At-Risk Youth. Journal of Abnormal Child Psychology, 43, 645-653.

https://doi.org/10.1007/s10802-014-9937-y

Zessin, U., Dickhäuser, O., \& Garbade, S. (2015). The Relationship between Selfcompassion and Well Being: A Meta Analysis. Applied Psychology: Health and Well Being, 7, 340-364. https://doi.org/10.1111/aphw.12051 